\title{
Two dose Augmentin treatment of acute gonorrhoea
} in men

\author{
K B LIM, V S RAJAN (Deceased), Y C GIAM, E O LUI, E H SNG, AND K L YEO \\ From the Middle Road Hospital, Singapore
}

SUMMARY We studied 192 men with acute gonococcal urethritis, 97 of whom received two oral doses of Augmentin (amoxycillin $3 \mathrm{~g}$ and clavulanic acid $250 \mathrm{mg}$ ) separated by a four hour interval; the remaining 95 received $2 \mathrm{~g}$ kanamycin in a single intramuscular injection. Of the patients treated with Augmentin, $93(95 \cdot 9 \%$ ) were cured, which was significantly more than the 83 $(87 \cdot 4 \%)$ patients treated with kanamycin. Augmentin was equally effective in the treatment of penicillinase producing Neisseria gonorrhoeae (PPNG) and non-PPNG infections, the cure rates for which were $96 \cdot 6 \%$ and $95 \cdot 6 \%$ respectively.

\section{Introduction}

The introduction of sulphonamides in 1937 and the use of penicillin since the second world war have failed to reverse the continuing worldwide increase in the incidence of gonorrhoea. Although the increase may be partly explained by a change in moral attitudes, two microbiological factors play a significant part. These are a gradual reduction in sensitivity of the gonococcus to penicillin and the emergence of $\beta$-lactamase, or penicillinase producing, Neisseria gonorrhoeae (PPNG). PPNG strains, which originated in West Africa and South East Asia, were first reported in 1976 in England and the United States of America. ${ }^{12}$ Since then, these strains have become well established in their regions of origin and have spread worldwide. ${ }^{3}$ Their ability to disseminate internationally threatens effective treatment of gonorrhoea with penicillin and other $\beta$-lactam antibiotics.

There have been two approaches to the $\beta$-lactamase problem. One has been the development of antimicrobials stable to $\beta$-lactamase, and the other has been the search for inhibitors of $\beta$-lactamase. Clavulanic acid isolated from Streptomyces clavuligerus is a potent inhibitor of $\beta$-lactamase. ${ }^{4}$ In combination with amoxycillin, it extends the antibacterial activity of amoxycillin to include $\beta$-lactamase producing strains, which are otherwise resistant. Earlier studies have shown that $\beta$-lactamase producing strains of $N$ gonorrhoeae resistant to

Address for reprints: $\operatorname{Dr}$ K B Lim, Middle Road Hospital, 250 Middle Road, Singapore 0718, Republic of Singapore

Accepted for publication 17 November 1983 amoxycillin at concentrations of $4-64 \mathrm{mg} / \mathrm{l}$ are susceptible to a combination of amoxycillin and clavulanic acid. ${ }^{56}$ Augmentin is a formulation comprising amoxycillin and the potassium salt of clavulanic acid. Both components are well absorbed by the oral route. Peak serum concentrations of $6.06 \mathrm{mg} / 1$ of amoxycillin and $4.22 \mathrm{mg} / 1$ of clavulanic acid were obtained after $1 \frac{1}{2}$ hours in patients receiving Augmentin $750 \mathrm{mg}$ (amoxycillin $500 \mathrm{mg}$ plus clavulanic acid $250 \mathrm{mg}$ ) by mouth.?

Augmentin appeared to be worth considering for the treatment of gonorrhoea in Singapore, where PPNG strains account for nearly $35 \%$ of all gonococcal strains isolated. Preliminary studies (unpublished) on the use of a single dose of Augmentin in the treatment of gonorrhoea showed a failure rate of about $29 \%$ for PPNG infections and $8 \%$ for non-PPNG infections. Antibiotic susceptibility tests showed no cases of in vitro resistance. Hence it was postulated that the poor results obtained with PPNG infections compared with non-PPNG infections were due to the short duration of effective clavulanic acid concentrations present in body fluids.

In this study, therefore, we chose to use two doses of Augmentin (amoxycillin $3 \mathrm{~g}$ plus clavulanic acid $250 \mathrm{mg}$ ) separated by a four hour interval.

\section{Patients and methods}

\section{STUDY POPULATION}

This study was conducted at the outpatient department of this hospital from December 1982 to May 1983 , and 200 men with acute gonococcal urethritis were recruited into the trial. Patients with a history of 
penicillin allergy or who had received antimicrobials over the 72 hours preceding the start of the study were excluded.

\section{DIAGNOSIS}

Gonorrhoea was diagnosed on the finding of Gram negative intracellular diplococci in stained smears and was subsequently confirmed on culture. Gonococcal isolates were recognised by their colonial morphology on modified Thayer-Martin medium, oxidase reaction, and Gram stained microscopic appearance. Penicillinase production was tested for in all isolates by the paper acidometric method. ${ }^{8}$

\section{TREATMENT}

Half the patients received two doses of Augmentin as described below, while the remaining 100 received $2 \mathrm{~g}$ of kanamycin in a single intramuscular injection. Augmentin was administered in a sachet containing amoxycillin $3 \mathrm{~g}$ and clavulanic acid $250 \mathrm{mg}$. The contents of the sachet were dissolved in a glass of water and were administered under supervision. The patient was then instructed to take the second dose after a four hour interval and given a second sachet with the time for taking the second dose indicated.

\section{FOLLOW UP AND TESTS OF CURE}

All patients were assessed on days 5 and 14 after treatment. Urethral smears and cultures were obtained at each visit. Treatment was assumed to have failed if the culture remained positive on day 5 and the patient denied having had further sexual intercourse. If gonococci were isolated on day 14 and the patient admitted having had sexual intercourse, then reinfection was assumed. The Venereal Diseases Research Laboratory (VDRL) test was performed before treatment and at six weeks and three months afterwards.

\section{Results}

\section{TREATMENT RESPONSE}

The results of treatment are shown in table I. Eight patients defaulted from follow up and were therefore excluded, leaving 192 patients for assessment.

Out of 97 cases treated with Augmentin there were four failures, giving an overall cure rate of $95 \cdot 9 \%$. Of 29 PPNG infections $28(96.6 \%)$ were eradicated, compared with $65(95 \cdot 6 \%)$ of 68 non-PPNG infections. Kanamycin successfully eradicated $20(83 \cdot 3 \%)$ of 24 PPNG infections and $63(88 \cdot 7 \%)$ of 71 non-PPNG infections, giving an overall success rate of $87 \cdot 4 \%$. Overall, Augmentin was significantly $\left(\chi^{2}=4 \cdot 55\right.$; $p<0.05)$ more effective than kanamycin. No side effects to Augmentin were recorded.
TABLE I Treatment response to two dose Augmentin

\begin{tabular}{lllr}
\hline & $\begin{array}{l}\text { Total } \\
\text { treated }\end{array}$ & $\begin{array}{l}\text { No (\%) } \\
\text { cured }\end{array}$ & \multicolumn{1}{c}{$\begin{array}{l}\text { No (\%) } \\
\text { failed }\end{array}$} \\
\hline $\begin{array}{l}\text { Augmentin (amoxycillin } 3 \mathrm{~g} \\
\text { + clavulanic acid 250 mg) } \\
\text { two 4 hourly oral doses }\end{array}$ & & & \\
$\quad$ PPNG & 29 & $28(96 \cdot 6)$ & $1(3 \cdot 4)$ \\
$\quad$ Non-PPNG & 68 & $65(95 \cdot 6)$ & $3(4 \cdot 4)$ \\
$\quad$ Total & 97 & $93(95 \cdot 9)$ & $4(4 \cdot 1)$ \\
$\begin{array}{l}\text { Kanamycin 2 g } \\
\text { intramuscularly }\end{array}$ & & & \\
$\quad$ PPNG & 24 & $20(83 \cdot 3)$ & $4(16 \cdot 7)$ \\
$\quad$ Non-PPNG & 71 & $63(88 \cdot 7)$ & $8(11 \cdot 3)$ \\
$\quad$ Total & 95 & $83(87 \cdot 4)$ & $12(12 \cdot 6)$ \\
\hline
\end{tabular}

\section{ANTIBIOTIC SUSCEPTIBILITY}

Tests for antibiotic susceptibility to Augmentin were performed on 29 PPNG and 68 non-PPNG isolates. The minimum inhibitory concentrations (MICs) were measured by the agar plate dilution method previously described. ${ }^{9}$ Augmentin (amoxycillin and clavulanic acid in a 2:1 ratio) was used in doubling dilutions from $8 \mathrm{mg} / 1$ to $0.125 \mathrm{mg} / \mathrm{l}$.

Table II shows that PPNG isolates were less susceptible than non-PPNG strains, with MICs of $1-4 \mathrm{mg} / 1$ compared with $0 \cdot 125-4 \mathrm{mg} / \mathrm{l}$. The geometric mean MICs for PPNG and non-PPNG isolates were 2.098 and $0.571 \mathrm{mg} / 1$ respectively. The distribution of their MICs differed significantly $\left(\chi^{2}=43 \cdot 60\right.$; $\mathrm{p}<0.001)$.

MICs for isolates taken before and after treatment from four patients whose treatment failed were identical or differed by only one dilution. Of these, three were non-PPNG isolates with MICs of 0.25 , 0.25 , and $0.5 \mathrm{mg} / 1$ before treatment, and one was a PPNG isolate with an MIC of $4 \mathrm{mg} / \mathrm{l}$ before treatment.

TABLE II Susceptibility of $N$ gonorrhoeae to Augmentin

\begin{tabular}{llllllll}
\hline & \multicolumn{7}{c}{ No inhibitied by MICs (mg/l) of: } \\
\cline { 2 - 7 } Strains (No) & 0.125 & 0.25 & 0.5 & 1 & 2 & 4 \\
\hline PPNG (29) & 1 & 22 & 21 & 14 & 7 & 3 \\
\hline Non-PPNG (68) & 1 & &
\end{tabular}

$\chi^{2}=43 \cdot 60 ; p<0 \cdot 001$

\section{Discussion}

PPNG strains were first isolated in Singapore late in 1976. ${ }^{10}$ Since then they have been found increasingly, and in 1982 accounted for $34.5 \%$ of all gonococcal strains isolated here. Clearly, an antibiotic effective against both PPNG and non-PPNG strains is potentially useful in the treatment of gonorrhoea in Singapore. 
We achieved an overall cure rate of $95.9 \%$ with two doses of Augmentin (amoxycillin $3 \mathrm{~g}$ and clavulanic acid $250 \mathrm{mg}$ ) separated by a four hour interval. This regimen was equally effective for PPNG and non-PPNG infections, the cure rates for which were $96.6 \%$ and $95.6 \%$ respectively. No side effects were recorded. This study therefore confirms that Augmentin used as above is very effective against all strains of $N$ gonorrhoeae. The results compare favourably with those obtained with spectinomycin ${ }^{11}$ and cefotaxime. ${ }^{12}$ Furthermore, Augmentin can be safely and easily administered (orally).

Surprisingly, initial studies using single dose Augmentin (amoxycillin $3 \mathrm{~g}$ and clavulanic acid $250 \mathrm{mg}$ ) resulted in cure rates of only $71.4 \%$ for PPNG infections and $\mathbf{9 2 . 3 \%}$ for non-PPNG infections. It was postulated that the duration of an effective clavulanic acid serum concentration with a single dose was insufficient to provide maximum inhibition of penicillinase. The significantly improved cure rate obtained with the two dose Augmentin regimen indirectly lends support to the above hypothesis.

The poor results of single dose Augmentin treatment are, however, difficult to explain conclusively. A study conducted in the Philippines by Lao et al using Augmentin (amoxycillin $3 \mathrm{~g}$ and clavulanic acid $125 \mathrm{mg}$ ) for the treatment of PPNG infections recorded a cure rate of $92 \% .{ }^{13}$ Another study conducted in Amsterdam by Tio et al using Augmentin (amoxycillin $3 \mathrm{~g}$ and clavulanic acid $0.5 \mathrm{~g}$ ) plus probenecid $1 \mathrm{~g}$ resulted in a similar cure rate of $93.6 \%$ for PPNG infections. ${ }^{14}$ What then, might be the reasons for the differences in cure rates between our studies and studies conducted elsewhere? Differences in the antimicrobial susceptibility of PPNG strains may be a factor, as the authors mentioned did not report the MICs for their isolates. Another factor may be individual variation in the pharmacokinetics of clavulanic acid in the body. A third possibility is that strains of PPNG found in Singapore may produce more penicillinase, and therefore require more clavulanic acid to neutralise it. Further studies are necessary to provide an answer.

In conclusion, two doses of Augmentin (amocycillin $3 \mathrm{~g}$ and clavulanic acid $250 \mathrm{mg}$ ) separated by a four hour interval constitute an effective treatment for gonorrhoea. Augmentin permits simple oral treatment and is well tolerated. Its use should be considered in areas where PPNG is prevalent.

We thank Dr O P W Robinson of Beechan Pharmaceuticals (International Division) for supplying the Augmentin.

\section{References}

1. Phillips I. $\beta$-lactamase producing, penicillin-resistant gonococcus. Lancet 1976; ii:656-7.

2. Ashton WA, Golash RG, Hemming VG. Penicillinase-producing Neisseria gonorrhoeae. Lancet 1976; ii: 657-8.

3. Perine $\mathbf{P}$, Morton $\mathrm{RS}$, Piot $\mathbf{P}$, Siegel MS, Antal GM. Epidemiology and treatment of penicillinase-producing Neisseria gonorrhoeae. Sex Transm Dis 1979; 6 suppl:152-8.

4. Reading C, Cole M. Clavulanic acid: a beta lactamase inhibiting beta lactam from Streptomyces clavuligerus. Antimicrob Agents Chemother 1977;11:852-7.

5. Miller JM, Baker CN, Thornsberry C. Inhibitor of $\beta$-lactamase in Neisseria gonorrhoeae by sodium clavulanate. Antimicrob Agents Chemother 1978; 14:794-6.

6. Piot D, Van Dyck E, Colaert J, Ursi JP, Bosman E, Mehus A Antibiotic susceptibility of Neisseria gonorrhoeae strains from Europe and Africa. Antimicrob Agents Chemother 1979; 15:535-9.

7. Saito A. The pharmacokinetics of BRL-25000-Augmentin in humans. In: Augmentin. Proceedings of an international symposium, Montreux: Excerpta Medica, 1981;34-46.

8. Sng EH, Yeo KL, Rajan VS. Simple method for detecting penicillinase-producing Neisseria gonorrhoeae and Staphylococcus aureus. Br J Vener Dis 1981;57:141-2.

9. Sng EH, Rajan VS, Pang R, Yeo KL. Susceptibility of Neisseria gonorrhoeae to cefotaxime and ceftrizoxime. Br J Vener Dis 1981;57:162-4.

10. Rajan VS, Sng EH, Khoo R, Tan T, Tan NJ. Beta-lactamase strains of gonococci in Singapore. Asian Journal of Infectious Diseases 1977;1:62.

11. Rajan VS, Leong YO. Spectinomycin hydrochloride treatment of gonorrhoea. Singapore Med J 1972;13:161-2.

12. Rajan VS, Sng EH, Pang R, Tan NJ, Thirumoorthy T, Yeo KL. HR-756 a new cephalosporin in the treatment of gonorrhoea caused by ordinary and penicillinase-producing strains of Neisseria gonorrhoeae. Br J Vener Dis 1980; 56:255-8.

13. Lao LM, Lao MLM. A combination of amoxycillin and clavulanic acid in the treatment of acute male penicillinresistant gonorrhoea in the Philippines. In: Augmentin. Proceedings of an international symposium. Montreux: Excerpta Medica, 1981:222-6.

14. Tio D, de Koning GAJ, Ansink-Schipper MC, Coutinho RA. Augmentin in the treatment of gonorrhoea caused by penicillinase-producing gonococci. In: Augmentin. Proceedings of the European symposium. Scheveningen, The Netherlands: Excerpta Medica, 1982:218-21. 